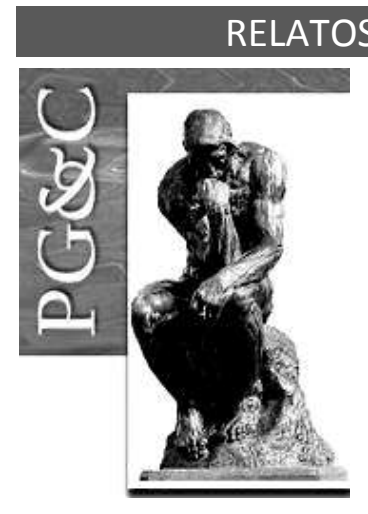

\title{
APRENDIZAGEM ORGANIZACIONAL EM REDES SOCIAIS: UM ESTUDO CIENTOMÉTRICO
}

\author{
Jordana Kelly Belarmino da Silva \\ Mestranda em Ciência da Informação pela Universidade Federal da \\ Paraíba, Brasil. \\ E-mail: jkbella7@gmail.com. \\ Victória Lopes Felix \\ Mestranda em Ciência da Informação pela Universidade Federal \\ da Paraíba, Brasil. \\ E-mail: victorialf95@gmail.com \\ Marynice de Medeiros Matos Autran \\ Doutora em Informação e Comunicação em Plataformas Digitais \\ pela Universidade do Porto, Portugal. \\ Professora da Universidade Federal da Paraíba \\ E-mail: marynice.autran@gmail.com
}

\begin{abstract}
Resumo
Apresenta uma análise cientométrica da produção científica sobre Aprendizagem Organizacional em Redes Sociais. A cientometria estuda a progressão da ciência através de métodos e análises quantitativas, proporcionando a mensuração da produção científica de instituições, pesquisadores e temáticas que estão inseridos no universo científico. A problemática que norteia esta pesquisa é pautada nos seguintes questionamentos: qual a origem geográfica e o volume de artigos publicado nos últimos cinco anos sobre a temática aprendizagem organizacional em redes sociais em nível nacional e internacional? A partir desse questionamento delimitamos o seguinte objetivo: analisar a produção científica sobre a temática Aprendizagem Organizacional em Redes Sociais no período 2014 a 2018. A busca foi realizada na base de dados Scopus utilizando os seguintes descritores: "aprendizagem organizacional" AND "redes sociais" e "organizational learning" AND "social networks ". Após a utilização de filtros foram recuperados e analisados 46 artigos, tendo como autoria e coautoria pesquisadores com mais 30 nacionalidades e instituições. A produção científica recuperada indica que a área se encontra em crescimento, visto que no ano de 2018 houve um incremento, de $48 \%$ no período analisado. Constatou-se, também, que tanto as instituições quanto os autores produziram colaborativamente, tornando explícita a existência de redes de coautoria, o que permite afirmar a existência de interação e compartilhamento de conhecimento e informações entre os atores e instituições. Verificou-se também que apenas 33\% das pesquisas receberam financiamento das agências de fomento. Fazendo uso cientometria foi possível descrever o prestígio e o poder exercido por países, instituições, pesquisadores, periódicos e agências de fomento com relação à produção científica acerca do tema analisado.
\end{abstract}

Palavras-chave: Aprendizagem Organizacional. Redes Sociais. Aprendizagem Organizacional em Redes Sociais.

ORGANIZATIONAL LEARNING IN SOCIAL NETWORKS: A SCIENTOMETRIC STUDY

Abstract

This research presents a scientometric analysis of the scientific production about Organizational Learning in Social Networks. Scientometrics studies the progress of science through quantitative methods and

Perspectivas em Gestão \& Conhecimento, João Pessoa, v. 10, número especial, p. 160-175, mar. 2020. DOI: http://dx.doi.org/10.21714/2236-417X2020v10nep160

http://periodicos.ufpb.br/ojs2/index.php/pgc. ISSN: 2236-417X. Publicação sob Licença (cc) EY-NC-ND 
analysis, providing the measurement of the scientific production of institutions, researchers and themes inserted in the scientific universe. The problem that guides this research is based on the following question: what is the geographical origin and the volume of articles published in the last five years on the theme organizational learning in social networks at national and international level? From this questioning we delimited the following objective: to analyze the scientific production on the theme Organizational Learning in Social Networks from 2014 to 2018. The search was carried out in the Scopus database using the following descriptors: "aprendizagem organizacional" AND "redes sociais" and "organizational learning "AND "social networks ". After using filters, 46 articles were retrieved and analyzed, having as authorship and co-authoring researchers from over 30 nationalities and institutions. The production related to the theme is growing, since in 2018 there was an increase, making up 48\%. For the vast majority both institutions and authors produced collaboratively, making explicit the existence of co-authoring networks, from which there is interaction and sharing of knowledge and information between actors and Institutions. It was also found that only 33\% of the research received funding from development agencies. Using scientometric methods, it became possible to describe the prestige and power exercised by countries, institutions, researchers, journals and funding agencies in relation to scientific productions on the analyzed topic.

Keywords: Organizational Learning. Social Networks. Organizational Learning in Social Networks.

\section{INTRODUÇÃO}

Aprender é uma atividade inerente ao ser humano. Na realidade, o processo de aprendizagem é algo que nos acompanha em todas as etapas da vida, seja por necessidade de sobrevivência, seja pela competitividade no mundo do trabalho, seja por evidência social, destaque profissional, busca de progresso ou, até mesmo, por razões de exercício cerebral.

Na perspectiva de Carvalho (1999), o processo de aprendizagem está intrinsecamente relacionado ao existir humano, em um processo constante de curiosidade, de querer compreender para satisfazer a necessidade de conhecer. $O$ autor destaca que o indivíduo vive em constante ressignificação, a rever suas concepções desde que convicto da necessidade de mudança em sua forma de pensar ou agir.

Dentre os vários tipos de aprendizagem, evidenciamos a aprendizagem organizacional que tem emergido com vigor nos últimos anos e vem ganhando evidência na literatura em nível nacional e internacional. O processo de inserção da aprendizagem organizacional envolve diversas variáveis, que consiste na geração de conhecimento, por intermédio de relações dinâmicas dos indivíduos, bem como, dos ambientes internos e externos à organização (ZANGISKI; LIMA; COSTA, 2009)

As interações sociais que ocorrem no ambiente organizacional propiciam esse tipo de aprendizagem, pois o compartilhamento de conhecimentos entre indivíduos nesse contexto estimula a aprendizagem organizacional através de redes sociais, onde os atores trocam e somam experiências e aprendizados, contribuindo para a evolução e ganho das organizações das quais fazem parte.

Nessa perspectiva, a problemática que norteia esta pesquisa é pautada no seguinte questionamento: qual o volume e características (origem geográfica e institucional, periódico, financiamento e idioma) dos artigos publicados os últimos cinco anos (2014-2018) sobre a temática aprendizagem organizacional em redes sociais em nível nacional e internacional?

Para responder à essa questão delimitamos o seguinte objetivo: analisar a produção científica sobre a temática Aprendizagem Organizacional em Redes Sociais no período 2014 a 2018.

Perspectivas em Gestão \& Conhecimento, João Pessoa, v. 10, número especial, p. 160-175, mar. 2020. 


\section{GESTÃO DA INFORMAÇÃO E DO CONHECIMENTO}

A informação em consonância com o conhecimento são as molas propulsoras do século XXI. O caráter interdisciplinar da informação, permite que ela se enquadre em diversas áreas do conhecimento, representada por diferenciados conceitos.

Para Choo (2003) a informação é intrínseca a quase toda organização, e sua compreensão se faz necessária para transformar a informação em percepção, conhecimento e gerar ações. É preciso perceber o ambiente interno e externo na perspectiva de criação de significado das informações coletadas e assim gerar a construção de conhecimento, culminando com a tomada de decisão.

A gestão da informação consiste em compreender a necessidade do ambiente no qual ela está situada, e utilizar de mecanismos da gestão para melhorar o desempenho de sua aquisição, armazenamento, recuperação e uso, para construir uma organização inteligente que busque o conhecimento, aprendizagem e inovação constantemente.

Por outro lado, a gestão do conhecimento é o processo no qual os indivíduos partilham seu capital intelectual adquirido por meio de informações e experiência, com o objetivo de gerar melhorias e inovações para a organização. Bukowitz e Williams (2002) conceituam a gestão do conhecimento como o processo em que as organizações constroem o seu capital financeiro, por meio das estratégias de compartilhamento do conhecimento dos indivíduos que a compõem.

O processo que envolve a gestão do conhecimento tem como fundamento dois tipos de conhecimento: o explícito, identificado em fontes registradas (livros, artigos, revistas, blogs etc.,) bem como em comunicação dialogada, e o conhecimento tácito, aquele no qual o indivíduo o constrói com as experiências ao longo da sua existência.

A inserção da gestão do conhecimento no ambiente organizacional exige dos indivíduos a cultura do conhecimento, transformando o conhecimento tácito em explícito de modo contínuo, utilizando modelos que vão variar de acordo com os objetivos, serviços e produtos, de acordo com as atividades da organização. O conhecimento externalizado, compartilhado e armazenado constrói uma base para a organização que redunda em desenvolvimento e inovações (NONAKA, TAKEUCHI, 1997).

Utilizando esses dois tipos de conhecimento Nonaka e Takeuchi (1997) produziram a espiral do conhecimento (Figura 1) com campos criados a partir da relação do conhecimento tácito e o conhecimento explícito que ilustra o processo da gestão do conhecimento:

Figura 1 - Espiral do Conhecimento

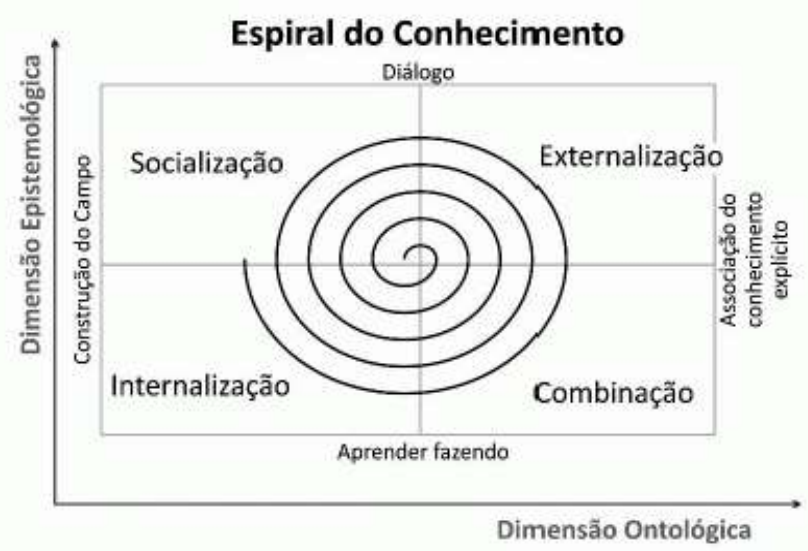

Fonte: Nonaka e Takeuchi (1997)

Perspectivas em Gestão \& Conhecimento, João Pessoa, v. 10, número especial, p. 160-175, mar. 2020. 
A espiral do conhecimento é composta pela socialização, que é o processo de compartilhar experiências, ou seja, conhecimento; a externalização é composta da transformação do conhecimento tácito em conceitos explícitos; a internalização é o processo constituído da conversão do conhecimento explícito em tácito; a combinação é composta da combinação de diferentes conhecimentos explícitos.

Para a que o processo de gestão do conhecimento ocorra na organização é necessário que a aprendizagem seja uma constante no cotidiano, que se torne uma realidade na cultura do ambiente. Dessa forma, aprender não se restringe à leitura de livros e uma sala de aula, mas e/ou principalmente, à experiências, comportamentos, comunicação, interações, redes sociais, entre outras atividades que possibilitam uma gestão do conhecimento organizacional.

\section{APRENDIZAGEM ORGANIZACIONAL}

Aprender é um processo constante na sociedade, os indivíduos participam ativamente aprendendo e compartilhando conhecimento em todas as fases da vida, direta ou indiretamente. Nas organizações o modo de aprendizagem envolve diversos pressupostos, como: implementar esse processo na cultura da organização; se o processo será individual, coletivo ou ambos.

Aprender é trilhar caminhos desconhecidos e superfícies inexploradas, de maneira que a aprendizagem no contexto organizacional não se dá de forma individualista, mas parte de relações sociais de compartilhamento de conhecimentos pelos membros da organização, onde a caminhada em busca de novos horizontes de aprendizado se traduz como uma atividade social. Nesse contexto, a promoção de conhecimento acontece a partir das interações sociais dos indivíduos na obtenção de experiências que passam a direcioná-las para a organização, caminhando para o estágio de conhecimento organizacional, promovendo redes sociais de aprendizagem.

As organizações compreendem o capital intelectual dos seus membros não apenas pelo que já está estabelecido em seu conhecimento prévio, sua legitimidade está em se inserir e compreender o processo constante de aprendizado, a se estabelecer na cultura organizacional como recurso estratégico para inovação (BUKOWITZ; WILLIAMS, 2002).

Burnham et al. (2005) referem que a aprendizagem é um processo de compreensão de mundo, com aprendizes buscando novas informações e experiências para reorganizar o conhecimento em um ciclo constante. Para as organizações esse processo necessita manter-se vivo, pois o ambiente funciona como uma espiral, sempre se retroalimentando com novas aprendizagens e conhecimentos que culminam em inovação.

Para a implementação de um ambiente organizacional de aprendizagem é necessário a implementação de três fases: adaptação, capital intelectual e contribuição/compartilhamento. A aprendizagem nesse ambiente ocorre quando seus membros se conscientizam da importância do processo educacional que se adquire com a experiência, e da relevância de compartilhar com o grupo os conhecimentos adquiridos. É um processo que se torna efetivo quando a atividade se tornar uma constante no cotidiano da organização (ANTONELLO, 2005).

A aprendizagem organizacional se consolida por meio do compartilhamento resultante do conhecimento adquirido a partir das experiências. Isso permite o desenvolvimento de novos significados, habilidades e competências, que geram vantagem competitiva e inovação, mola propulsora para o crescimento mercadológico e consequentemente financeiro das organizações.

A construção de um ambiente de aprendizagem organizacional pode ser tratada com dinamicidade, proporcionando a construção de uma organização pautada na criação de novos conhecimentos, para ser compartilhado em todos as estruturas hierárquicas da organização e

Perspectivas em Gestão \& Conhecimento, João Pessoa, v. 10, número especial, p. 160-175, mar. 2020. 
assim, gerar inovações a serem incorporadas aos produtos, serviços e sistemas (NONAKA, TAKEUCHI, 1997).

No processo de compartilhamento, uma estratégia é a utilização de redes, que de acordo com Tomaél, Alcará e Di Chiara (2005) acentua a capacidade de inovação individual e organizacional, promovendo maiores possibilidades de interação entres os indivíduos da organização, ampliando a eficiência e a eficácia no processo de construção de inovação.

A redes que compõem o processo de compartilhamento de informação e conhecimento organizacional, são ativos da aprendizagem. A interação entres os indivíduos, interno e externo ao ambiente de trabalho interfere no processo de aprendizagem e deve ser levado em consideração, permitindo que esses ativos adicionais fortaleçam a cultura interna, no que concerne ao compartilhamento, ao aprendizado e à inovação.

\title{
4 REDES SOCIAIS E DE COMPARTILHAMENTO
}

"A palavra 'rede' deriva do Latim vulgar rete, significando malha, artefato para capturar aves, caças ou peixes" (Ferreira, 2011; Silva, 2012, p. 43). Analogamente, a rede, como uma teia, captura informações. "Com laços e entrelaços, conecta indivíduos no ciberespaço e torna visível a extensão e intensidade das interações sociais dos atores que a compõem" (AUTRAN, 2015, p.92).

De acordo com Portugal (2007, p.3-4) "[...] a popularidade do conceito de rede e o reconhecimento das suas capacidades descritivas e explicativas ultrapassam hoje os limites das ciências sociais e estendem-se, cada vez mais, a outros domínios científicos". Partindo de um contexto geral, as redes podem ser definidas como um conjunto de indivíduos e/ou objetos que se encontram interligados, onde pode acontecer o compartilhamento e circulação de componentes materiais e imateriais, sejam essas ações realizadas entre indivíduos ou organizações.

O conceito de rede - pontos unidos por linhas -, portanto, traz na sua essência elementos primitivos da ciência que permitiu construir e consolidar as habilidades de perceber o real e atribuir-Ihe significado (VERMELHO, MACHADO VELHO E BERTONCELLO, 2015).

Nessa perspectiva, compreende-se que:

\begin{abstract}
As estruturas sociais podem ser representadas como redes - como conjuntos de nós (ou membros do sistema social) e conjuntos de laços que representam as suas interconexões. [...]. Usualmente, os estruturalistas têm associado nós com indivíduos, mas eles podem igualmente representar grupos, corporações, agregados domésticos, ou outras coletividades. Os laços são usados para representar fluxos de recursos, relações simétricas de amizade, transferências ou relações estruturais entre nós (WELLMAN; BERKOWITZ, 1991 apud PORTUGAL, 2007, p. 6).
\end{abstract}

Em essência, o ser humano desde seu nascimento adentra à sociedade utilizando-se de relações sociais, que de início e sem fazer nenhum tipo de escolha, passa a participar de um grupo social denominado família, e daí por diante surgem os grupos escolares, comunitários, círculos de amizades, religiosos e de trabalho, de maneira que uma nova rede se constrói em sua volta, sem sequer dar-se conta de tal acontecimento.

"Rede seria um conjunto de pontos interligados, ou um conjunto de nós e linhas organizado de forma não-hierárquica" (MARTINHO, 2003, p. 17) Corroborando com essa assertiva, Peixoto $(2006$, p. 50) define rede como "[...] estruturas auto-organizantes compostas de nós conectados por algum tipo de relação através da qual a comunicação pode ocorrer".

Perspectivas em Gestão \& Conhecimento, João Pessoa, v. 10, número especial, p. 160-175, mar. 2020. 
Na perspectiva das redes, os nós também chamados de atores, são representados por indivíduos, equipes, organizações ou conceitos, onde os laços apresentam a função de conectar esses atores, seja de forma direcionada ou não direcionada, dicotômica ou de valores (JESUS, 2019).

Sob a ótica de Tomaél, Alcará e Di Chiara (2005), nas redes sociais cada indivíduo tem uma função e identidade cultural. Sua relação com outros indivíduos vai formando um todo coeso que representa a rede. De acordo com a temática da organização da rede, é possível a formação de configurações diferenciadas e mutantes.

De acordo com Vermelho, Machado Velho e Bertoncello (2015), o que hoje as áreas do conhecimento reconhecem sob a denominação de rede social é uma construção linguística e cultural, apoiada sobre práticas observacionais que foram se constituindo ao longo da história humana.

Para Marteleto (2001, p. 72) "[...] rede social é representada como um conjunto de participantes autônomos, unindo ideias e recursos em torno de valores e interesses compartilhados". A autora ainda demonstra a dicotomia atrelada ao conceito da antropologia estrutural e do individualismo metodológico, onde a primeira o trata de forma descritiva, identificando o caráter contínuo característico das organizações e dos grupos sociais; o segundo, por sua vez, segue privilegiando a perspectiva do agente que produz sentido, e as relações sociais na formação do seu agir.

Santos e Sampaio (2016), referindo-se às redes sociais apontam três níveis distintos: o primeiro refere-se às equipes de trabalho; o segundo é voltado para as diversas equipes dentro de uma mesma organização; o terceiro retrata as redes interorganizacionais que ultrapassam os limites da própria organização.

\section{APRENDIZAGEM ORGANIZACIONAL EM REDES SOCIAIS}

Entende-se a aprendizagem como um processo cognitivo que se dá de forma individual por parte dos sujeitos, não obstante, nas organizações esse processo se materializa por meio de processos individuais, que só se torna viável com a intervenção mediadora exercida pelas organizações, onde seus membros interagem compartilhando conhecimentos e informações, configurando-se como um fenômeno de ordem social.

O crescimento da literatura sobre aprendizagem organizacional data das últimas décadas do século XX. Configura-se como principal aspecto relacionado ao seu crescimento o interesse por parte de administradores e acadêmicos pelo cenário competitivo, promovido pela emergência da economia global e a aceleração na dinâmica do mercado, o qual exigiu que as organizações aprimorassem seus produtos e processos (SMITH; VASUDEVAN; TANNIRU, 1996 apud SENA, 2010).

A partir da década de 1980 o conceito de aprendizagem organizacional emergiu com considerável ênfase, de maneira que seus princípios estavam estritamente enraizados na administração através de diversos fatores como estratégia na organização, cultura, estrutura, capacidade de absorção, resolução de problemas, competência, participação de funcionários, entre outros, os quais são responsáveis por determinar o resultado da aprendizagem (ANTONELLO, 2005)

Conforme apontado nas contribuições de Antonello (2005, p.16), "a aprendizagem organizacional pode ser vista como a busca para manter e desenvolver competitividade, produtividade e inovação em condições tecnológicas e de mercado incertas" Dessa forma, ela acontece por meio das interações sociais que promovem a troca de conhecimentos entre os membros da organização. Essas interações dão subsídios para a criação de nós e laços entre seus interagentes, proporcionando o surgimento de redes sociais de aprendizagem, as quais

Perspectivas em Gestão \& Conhecimento, João Pessoa, v. 10, número especial, p. 160-175, mar. 2020. 
podem ser vistas como redes sociais estudadas a partir das relações de aprendizagem estabelecidas entre seus atores, conforme observa Sena (2010).

Para Rodan (2008), a aprendizagem de ordem coletiva decorre-se através de interações repetidas e trocas entre os sujeitos, independentemente da existência de procedimentos operacionais ou atividades padronizadas para acontecerem. A aprendizagem ocorre de forma cotidiana nas organizações, constituindo-se como um aspecto dos padrões de participação dos indivíduos nas organizações, e não algo proveniente apenas de suas respectivas cabeças (SENA, 2010).

As redes de aprendizagem não são específicas nem tampouco promovidas apenas por determinados modelos de organizações, dado que os indivíduos aprendem em toda e qualquer organização, independentemente dela ser hierarquizada (SENA, 2010)

No âmbito das redes sociais existem três dimensões no contexto das estruturas organizacionais, elencadas por Sena (2010), a partir das contribuições de Poell e Van Der Krogt (2007), a saber:

a) a dimensão vertical - expressa as relações entre a alta direção e o núcleo operacional;

b) a dimensão horizontal - abarca as inter-relações entre colaboradores integrantes do mesmo nível hierárquico.

c) a dimensão externa - demonstra o impacto exercido na organização provocado pelos atores externos quando comparado a influência proposta pelos internos.

Nas redes sociais de aprendizagem são desenvolvidas relações que proporcionam o alcance de objetivos comuns a organização, podendo se tornar um instrumento de competitividade organizacional (JESUS, 2019).

Como componentes básicos das redes sociais de aprendizagem são apresentados os atores, as estruturas e os processos de aprendizagem. Os atores são considerados o centro das redes sociais de aprendizagem que interagem entre si proporcionando o desenvolvimento de políticas e programas de aprendizagem, bem como a execução de trilhas de aprendizagem. As estruturas de aprendizagem surgem das interações dos indivíduos ao realizarem na organização atividades de aprendizagem durante longos períodos de tempo (POELL et al, 2000).

As ligações existentes entre os atores da rede cumprem a função de canais de transferência de recursos tangíveis e intangíveis nas organizações (SANTOS; SAMPAIO, 2016). A inovação se constitui um produto desenvolvido pelos diversos atores engajados na rede, promovida através da interação existente entre esses atores, para a criação e compartilhamento de conhecimento dentro de ambientes organizacionais.

\section{PROCEDIMENTOS METODOLÓGICOS}

Os procedimentos metodológicos concretizam o caminho para o desenvolvimento da pesquisa científica no que diz respeito às técnicas, aos meios e aos fins. Como apresentado por Martins e Theóphilo (2016) a metodologia é edificada como o design que envolve técnicas de planejamento para obter um esboço para estruturar a pesquisa. Nessa perspectiva, o caminho percorrido foi conduzido na expectativa de responder à questão da pesquisa e aos objetivos propostos.

Levando em consideração o polo técnico quanto aos meios, essa pesquisa se enquadra como bibliográfica e documental. O cunho bibliográfico se refere ao levantamento realizado para a elaboração do marco teórico sobre Aprendizagem Organizacional em Redes Sociais. Conforme afirmam Prodanov e Freitas (2013) e Martins e Theóphilo (2016), o cunho

\footnotetext{
Perspectivas em Gestão \& Conhecimento, João Pessoa, v. 10, número especial, p. 160-175, mar. 2020.
} 
bibliográfico é fundamental para a elaboração do referencial teórico, indispensável na construção e embasamento de uma pesquisa científica. Por outro lado, apresenta também um cunho documental em virtude de a coleta de dados ter sido feita na base de dados Scopus, elegendo o período de 2014-2018, com a finalidade de verificar o número de artigos publicados no período e a origem institucional/geográfica dos autores.

Quantos aos fins, é uma pesquisa de caráter descritivo, uma vez que observa os dados, e os delineia sem interferir nos mesmos, seguindo os preceitos da pesquisa descritiva que "[...] observa, registra, analisa e ordena dados, sem manipulá-los, isto é, sem interferência do pesquisador" (PRODANOV; FREITAS, 2013, p. 52).

\subsection{0 caminho percorrido}

Inicialmente o fito da pesquisa era utilizar como fonte de dados os trabalhos publicados nos anais do KM Brasil ${ }^{1}$ e nas bases de dados Scielo, Web of Science (WoS) e Scopus.

Na base de dados Scopus foram identificados 46 artigos, na Scielo, 11 e na WoS apenas cinco. Dada a discrepância do número de artigos nas três bases de dados, julgamos que seria desproporcional a comparação. Dessa forma, modificamos as estratégias iniciais da pesquisa, restringindo-nos apenas à base de dados Scopus. Justificamos a opção de escolha da base de dados Scopus ${ }^{2}$ pelo número de artigos recuperados em relação às outras bases, para além de ser uma das maiores base de dados de resumos e citações da literatura (periódicos científicos, livros e anais de congressos) revisada por pares, abrangendo as áreas de tecnologia, medicina, ciências sociais e artes e humanidades; por contar com um sistema de ferramentas inteligentes para auxiliar no processo de recuperação da informação, e em especial por ter material suficiente e relevante para compor o escopo da pesquisa (MARTÍN; JIMÉNEZ-FANJUL; LEÓNMANTERO; MAZ-MACHADO, 2017)

A busca foi realizada utilizando os descritores ("aprendizagem organizacional" AND "redes sociais") e ("organizational learning" AND "social networks").

Os termos foram separados por aspas duplas, utilizando o operador booleano AND, indicando que os documentos recuperados deveriam conter todos os termos informados, abordando em sua completude a temática da pesquisa.

$\mathrm{Na}$ primeira busca, foram recuperados 9003 documentos. Dado este volume, aplicamos os seguintes filtros com a finalidade de recuperar artigos que fossem relevantes para os propósitos da pesquisa: a) área de Ciência Sociais; b) artigos exclusivamente publicados em periódicos de acesso aberto; c) artigo completo de periódico; e d) recorte temporal de cinco anos (2014-2018).

O filtro de acesso aberto foi utilizado para aceder o artigo na íntegra, uma vez que a base de dados contém títulos não contemplados no portal de periódicos da CAPES, o que impossibilita a leitura do artigo completo. $\mathrm{O}$ filtro para recorte de artigo completo de periódico refere-se à utilização específica de artigo completo, pois a base também indexa resumos expandidos, artigos completos, resumos de congressos, capítulos de livros, etc.

Por fim, o último filtro diz respeito ao recorte temporal fixado nos últimos cinco anos (2014-2018). Para a realização do recorte foi levado em consideração os anos em que a publicação sobre a temática foi realizada em anos consecutivos. $O$ único artigo indexado na

\footnotetext{
${ }^{1}$ Congresso Brasileiro de Gestão do Conhecimento, considerado o maior evento da América Latina no tema, onde os participantes têm acesso aos melhores casos de Gestão do Conhecimento, trabalhos científicos e painéis de discussão. Disponível em: www.kmbrasil.org/.

2 Disponível em: https://www.elsevier.com/pt-br/solutions/scopus. Acesso em: 06 de out. 2019.
}

Perspectivas em Gestão \& Conhecimento, João Pessoa, v. 10, número especial, p. 160-175, mar. 2020. 
base dados Scopus data do ano de 2009, mas com interrupção até o ano de 2014. Dessa forma, decidimos por considerar como início o ano de 2014.

Aplicados esses filtros, foram recuperados 115 artigos, os quais foram analisados a partir de sua leitura na íntegra, na perspectiva de identificar quais os artigos que realmente englobavam em sua completude a temática aprendizagem organizacional em redes sociais. A análise permitiu reduzir a 46 artigos, os quais estavam em consonância com todos os filtros aplicados.

Para a análise, utilizou-se a Cientometria, metodologia que trata do estudo dos aspectos quantitativos da ciência enquanto disciplina, na perspectiva de atividade e publicações científicas para compreender como e quanto os cientistas se comunicam (MACIASCHAPULA, 1998).

\section{ANÁLISE E DISCUSSÃO DOS RESULTADOS}

Os artigos selecionados, foram alvo de uma leitura minuciosa, considerando sua integralidade. Foram analisados quanto a sua compatibilidade com a temática que envolve a Aprendizagem organizacional em Redes Sociais. Nessa perspectiva identificamos que a produção científica publicada sob a forma de artigos de periódicos (indexados na base Scopus) nos últimos cinco anos (2014-2018) sobre a temática em apreço, atingiu 46 documentos, produzido por autores de 30 países.

\subsection{Evolução anual da produção}

Observamos que no período analisado ocorreu um crescimento constante da literatura temática. Iniciando timidamente em 2014, verificamos que em 2015 esse número duplicou, mantendo-se, a partir de então, em constante crescimento. Percebemos o ano de 2018 como o mais produtivo, com o total de 22 artigos, o que corresponde a $48 \%$ da produção do período analisado. Esse resultado sugere que o interesse dos pesquisadores das Ciências Sociais pela produção de trabalhos sobre a temática vem se expandindo nos últimos anos (Gráfico 1).

Gráfico 1 - Evolução da produção sobre a temática Aprendizagem Organizacional em Redes Sociais na base Scopus no período de 2014 a 2018

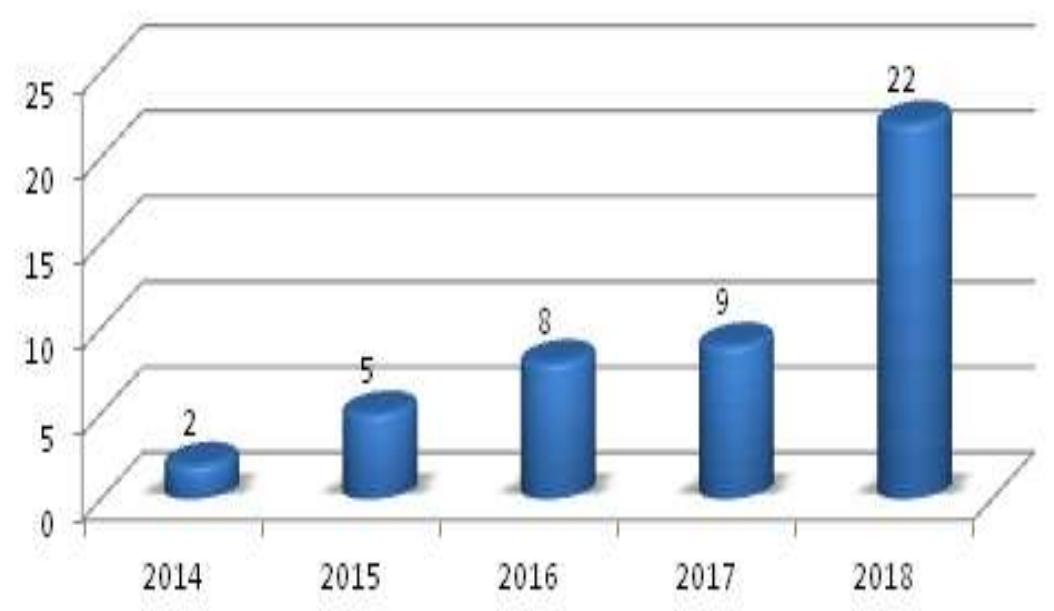

Fonte: Dados da pesquisa (2019)

Perspectivas em Gestão \& Conhecimento, João Pessoa, v. 10, número especial, p. 160-175, mar. 2020. 


\subsection{Autores e a produção científica}

Dentre os 46 artigos analisados, identificamos o total 157 coautorias, cujos atores são oriundos de universidades e centros de pesquisa. Esse total equivale 3,4 afiliações institucionais por artigo.

As instituições de maior destaque são: University of Electronic Science and Technology of China com oito, University of Rochester com seis, McGill University e a Universiti Teknologi Malaysia com cinco respectivamente. As demais apresentam um número corresponde a quatro e três coautorias, como demonstrado no Gráfico 2.

Em relação à produção brasileira, identificamos apenas um artigo produzido em colaboração internacional pela Universidade Federal de Santa Catarina, Faculdade SENAI CIMATEC, Universidade de Wisconsin-Madison (EUA) e a University of Sussex (Reino Unido).

Gráfico 2 - Autoria das publicações sobre a temática Aprendizagem Organizacional em Redes Sociais associadas a instituições indexadas na base Scopus no período de 2014 a 2018

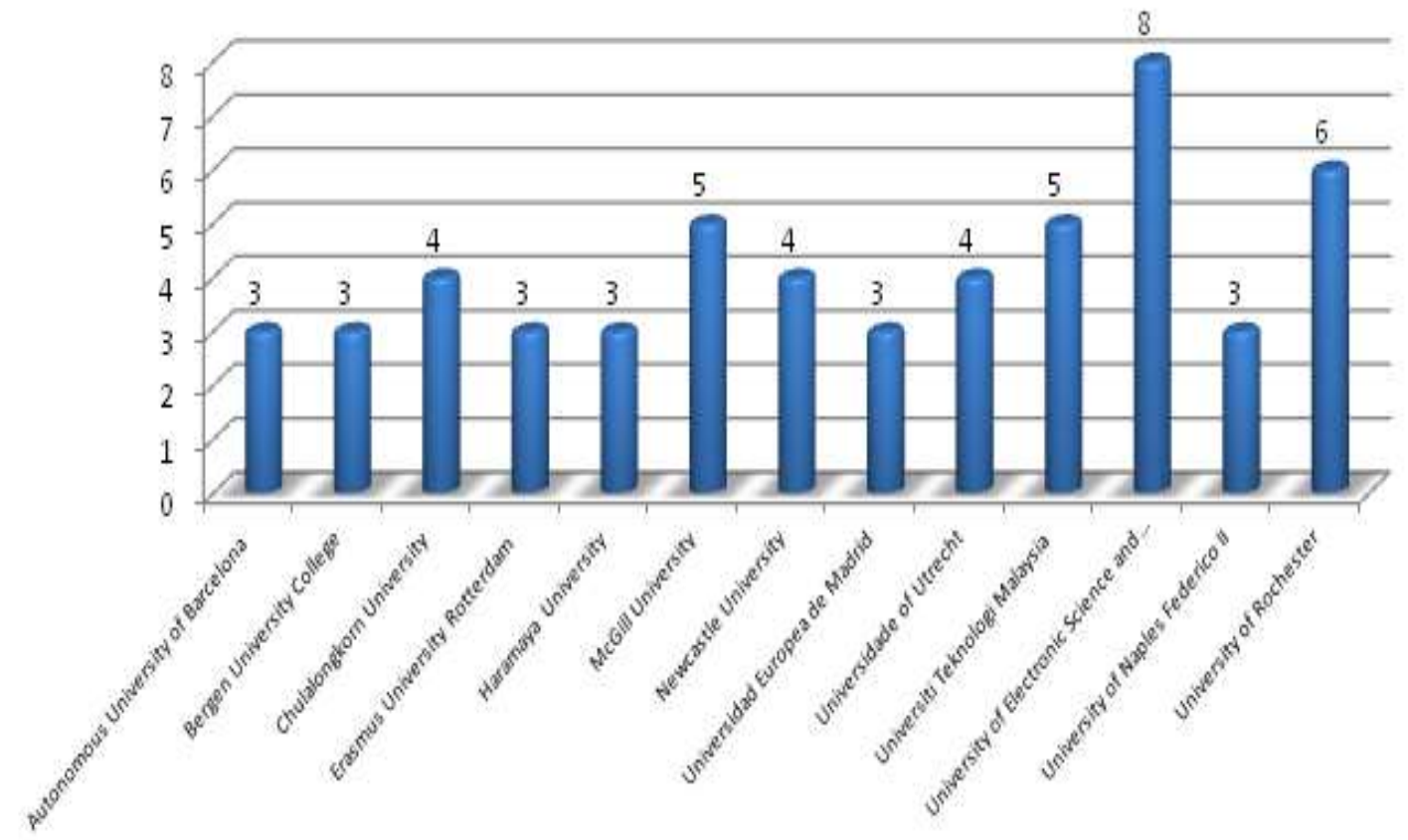

Fonte: Dados da pesquisa (2019)

Desde a segunda metade do século $X X$, mais precisamente em suas últimas décadas, verificamos a diversificação da origem dos cientistas na produção da literatura científica, dando subsídio para um incremento substancial na colaboração entre investigadores, e a crescente cooperação entre cientistas de diferentes nacionalidades e instituições.

No tocante a autoria dos trabalhos, identificamos apenas o pesquisador Francis Boadu (China), que apresenta a participação na produção de dois artigos. Como pesquisadores brasileiros destacam-se Jorge Luiz dos Santos e Renelson Ribeiro Sampaio, com um artigo produzido em colaboração, respectivamente.

Quanto ao idioma, constatamos a predominância dos artigos em inglês, de maneira que $94 \%(n=46)$ das pesquisas foram publicadas nesse idioma (Gráfico 3). Excetuando a língua inglesa, detectamos um artigo em Afrikaans $2 \%(n=1)$, um em Português $2 \%(n=1)$, e um em Espanhol 2\% (n=1).

Perspectivas em Gestão \& Conhecimento, João Pessoa, v. 10, número especial, p. 160-175, mar. 2020. 
Supomos que isso se deve ao fato de que a base de dados Scopus indexa, em sua maioria, periódicos publicados em inglês, uma vez que este é o idioma considerado universalmente como a linguagem científica. Isso tem como consequência a limitação da cobertura de periódicos que não publicam em inglês, revelando que os países em desenvolvimento enfrentam problemas com relação ao acesso à informação e publicação da ciência produzida, deixando de integrar a pesquisa nacional no contexto do conhecimento global (AUTRAN, 2015, p. 49).

Gráfico 3 - Idioma das publicações sobre a temática Aprendizagem Organizacional em Redes Sociais associadas a instituições indexadas na base Scopus no período de 2014 a 2018

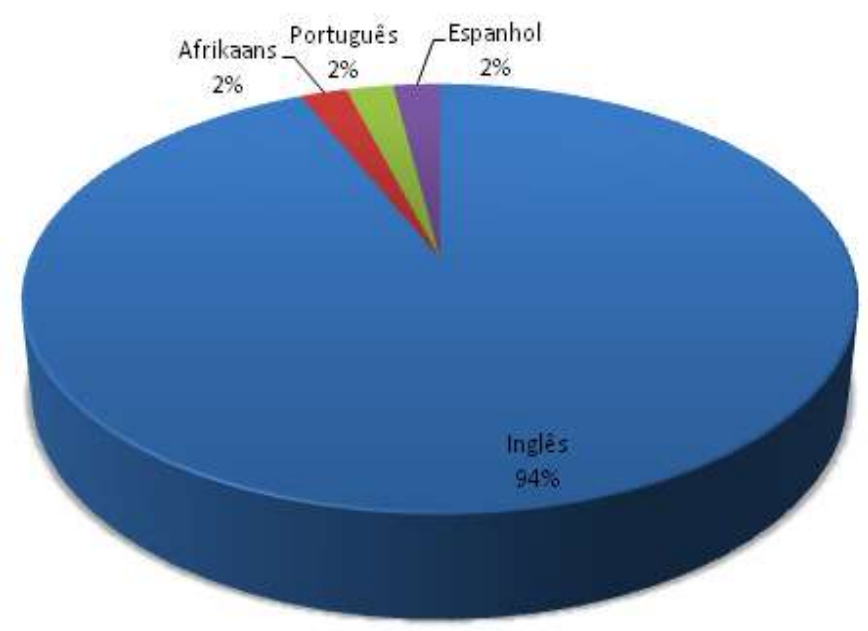

Fonte: Dados da pesquisa (2019)

\subsection{Financiamento de pesquisas}

Dos 46 artigos analisados, 15 (33\%) receberam financiamento de agências de fomento. Como em sua grande maioria os artigos foram produzidos em coautoria, tanto de pesquisadores como de instituições de ensino e de países, constata-se que o financiamento das pesquisas também aconteceu de forma colaborativa entre as mais diversas agências de financiamento. Identificamos 36 agências de fomento, dentre as quais destaca-se a National Natural Science Foundation of China, pelo financiamento de duas pesquisas, as demais financiaram apenas uma (Gráfico 4).

A colaboração para o financiamento de projetos propicia o crescimento e desenvolvimento da ciência e tecnologia de diversos países, onde pesquisadores de diferentes instituições e países firmam parcerias em pesquisas, de maneira a trazer contribuições individuais e coletivas para seus países, centros de pesquisas e instituições contribuindo assim para a ciência global (WAGNER, 2008).

Perspectivas em Gestão \& Conhecimento, João Pessoa, v. 10, número especial, p. 160-175, mar. 2020. 
Gráfico 4 - Percentual referente ao financiamento de pesquisas sobre a temática Aprendizagem Organizacional em Redes Sociais indexadas na base Scopus no período de 2014 a 2018

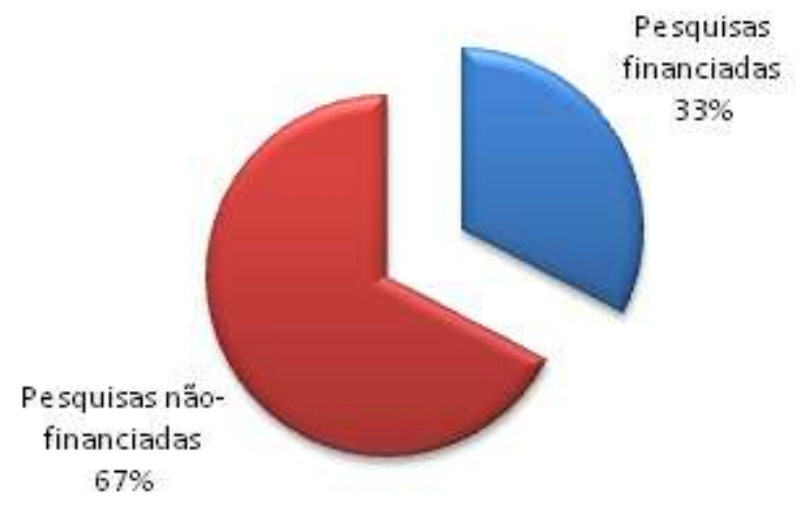

Fonte: Dados da pesquisa (2019)

\subsection{Mapeamento geográfico da afiliação institucional}

A afiliação institucional dos autores compreende 30 distintos países, tendo representatividade dos cinco continentes. A partir da análise realizada, percebemos que em sua grande maioria os pesquisadores têm como filiação instituições chinesas e americanas (19\%), seguindo-se os Países Baixos (17\%) e a Espanha (11\%). Dos países com maior número de colaborações destacam-se como sendo quatro europeus, dois americanos e dois asiáticos (Gráfico 5).

Gráfico 5 - Mapeamento geográfico da afiliação institucional das pesquisas sobre a temática Aprendizagem Organizacional em Redes Sociais indexadas na base Scopus no período de 2014 a 2018

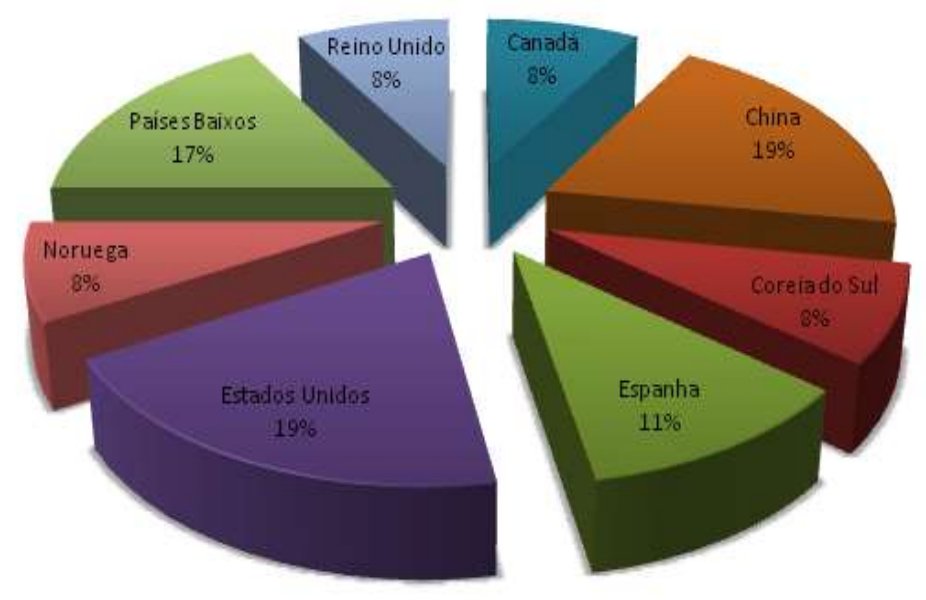

Fonte: Dados da pesquisa (2019).

Perspectivas em Gestão \& Conhecimento, João Pessoa, v. 10, número especial, p. 160-175, mar. 2020. 


\subsection{Frequência de publicação nos periódicos}

Com relação aos periódicos de livre acesso, identificamos o total de 28 títulos. Destes, destaca-se o periódico Sustainability. Trata-se de uma revista interdisciplinar, publicada na Suíça, que publicou o maior número de artigos sobre a temática $(30,4 \%)$. Em seguida, os periódicos International Journal of Emerging Technologies in Learning com 6,5\%, o International Journal of STEM Education, o Journal of Innovation and Entrepreneurship e o Marine Policy com 4,3\% cada, respectivamente.

A Tabela 1 mostra em ordem decrescente os periódicos que publicaram até dois artigos. Os demais periódicos publicaram apenas um artigo. Note-se que dentre estes, encontra-se o periódico brasileiro Perspectivas em Ciência da Informação, com um artigo publicado no ano de 2016, com o seguinte título: Informal social networks and knowledge diffusion: A modeling proposal applied to a software development environment.

Tabela 1 - Produção sobre a temática Aprendizagem Organizacional em Redes Sociais por periódico indexado na base Scopus no período de 2014 a 2018

\begin{tabular}{lcc}
\hline Periódico & No de artigos recuperados & Percentual (\%) \\
\hline Sustainability (Switzerland) & 14 & $30,4 \%$ \\
$\begin{array}{l}\text { International Journal of Emerging } \\
\text { Technologies in Learning }\end{array}$ & 3 & 6,5 \\
International Journal of STEM Education & 2 & 4,3 \\
Journal of Innovation and Entrepreneurship & 2 & 4,3 \\
Marine Policy & 2 & 4,3 \\
\hline
\end{tabular}

\section{CONSIDERAÇÕES FINAIS}

A análise da produção científica sobre a temática Aprendizagem Organizacional em Redes Sociais, revelou que a temática se encontra em ascensão, mostrando uma acentuada tendência de crescimento no período analisado. $O$ ano que se destaca com maior produção é 2018 , apresentando $48 \%$ de toda produção. Isso evidencia que a aprendizagem organizacional em redes sociais tem sido alvo de preocupação nas organizações, ensejando novas pesquisas, como comprovado no incremento da produção científica no período analisado.

Outro ponto a destacar é a produção em colaboração, não apenas entre autores, mas entre instituições, os quais foram fortemente identificados na análise, de forma que cada artigo apresentou um número referente a 3,4 autorias institucionais para cada pesquisa. Nesse contexto a University of Electronic Science and Technology of China, a University of Rochester, a McGill University e a Universiti Teknologi Malaysia, foram as instituições que mais se destacaram no trabalho colaborativo interinstitucional. Veja-se, assim, que os dois países asiáticos (China e Malásia) e os dois norte-americanos (Estados Unidos e Canadá) tiveram os maiores destaques.

As agências de fomento, cuja finalidade é o apoio financeiro para o desenvolvimento das pesquisas realizadas pelas universidades e centros de pesquisa, comparecem timidamente

Perspectivas em Gestão \& Conhecimento, João Pessoa, v. 10, número especial, p. 160-175, mar. 2020. 
nos trabalhos analisados, uma vez que constatamos financiamento para apenas $33 \%$ das pesquisas realizadas.

De acordo com o mapeamento das afiliações institucionais dos autores, percebemos a liderança de duas potências mundiais: a China e os Estados Unidos, que lideram o ranking de instituições que mais produzem sobre a temática em apreço, seguido pelos Países Baixos e pela Espanha.

O único autor que participou como coautor em mais de um artigo é oriundo da University of Electronic Science and Technology of China e o periódico com maior número de trabalhos publicados sobre a temática é o Sustainability, um periódico suíço, que publicou $30,4 \%$ dos artigos recuperados, o que se torna curioso, pois trata-se de uma publicação originária de um país europeu (Suíça) que não aparece no ranking de autores/ instituições mais produtivas.

Diante do exposto, verificamos que a produção ultrapassa os limites institucionais e geográficos, e segue a tendência de a produção científica apresentar-se de forma colaborativa interinstitucionalmente, ao invés de individualmente, comprovando a existência de redes colaborativas de coautoria, proporcionando a interação e compartilhamento de informação e conhecimento pelos autores que nutrem interesse pela temática em destaque.

Por fim, o estudo cientométrico possibilitou a mensuração do "poder" e do "prestígio" científico de países, de universidades, centros de pesquisas e de autores no tocante à temática analisada (SILVA; BIANCHI, 2001).

\section{REFERÊNCIAS}

ANTONELLA, C. S. A metamorfose da aprendizagem organizacional: uma revisão crítica. In: RUAS, R. L.; ANTONELLO, C. S.; BOFF, L. H. Os novos horizontes: aprendizagem organizacional e competências. Porto Alegre: Bookman, 2005.

AUTRAN, M. M. M. Comunicação da ciência, produção científica e rede de colaboração acadêmica: análise dos Programas brasileiros de Pós-Graduação em Ciência da Informação. Tese (Doutorado em Ciência da Informação) - Universidade do Porto. Porto: Universidade do Porto, 2015.

BARABÁSI, A. L. Linked: How Everything is Connected to Everything else and what it means for Business, Science and Everyday Life. Cambridge, MA: Plume, 2003.

BUKOWITZ, W. R.; WILLIAMS, R. L. Manual de gestão do conhecimento: ferramentas e técnicas que criam valor para a empresa. Porto Alegre: Bookman, 2002.

BURNHAM, T. F., et al. Aprendizagem organizacional e gestão do conhecimento. In: VI CINFORM - Encontro Nacional de Ciência da Informação, 6., 2005, Salvador. Anais [...]. Salvador: UFBA, $2005 . \quad$ Disponível em: http://www.cinformanteriores.ufba.br/vi anais/docs/TeresinhaRenatolsabelRamone.pdf. Acesso em: 01 nov. 2019.

CARVALHO, A. V. Aprendizagem organizacional em tempos de mudança. São Paulo: Pioneira, 1999.

Perspectivas em Gestão \& Conhecimento, João Pessoa, v. 10, número especial, p. 160-175, mar. 2020. 
CHOO, C. W. A Organização do Conhecimento: como as organizações usam a informação para criar significado, construir conhecimento e tomar decisões. Tradução Eliana Rocha. São Paulo Senac, 2003.

FERREIRA, C.; COSTA, A. Redes de coautoria e colaboração institucional nas ciências da saúde: análise evolutiva a partir de star scientists nacionais. Revista da Faculdade de Letras Geografia - Universidade do Porto, v. 2, p. 227-248, 2013.

JESUS, J. S. Uma análise dos efeitos das redes sociais de aprendizagem no resultado econômico e social de empreendimentos econômicos solidários. 2019. Tese (Doutorado em Ciências Sociais) - Programa de Pós-graduação em Ciências Sociais, Universidade do Vale do Rio dos Sinus, São Leopoldo, 2019.

MACIAS-CHAPULA. C. A. O papel da informetria e da cienciometria e sua perspectiva nacional e internacional. Ciência da Informação, Brasília, v. 27, n. 2, p. 134-140, maio/ago. 1998.

MARTELETO, R. M. Análise de redes sociais: aplicação nos estudos de transferência da informação. Ciência da Informação, Brasília, v. 30, n. 1, p. 71-81, jan./abr. 2001.

MARTINHO, C. Redes: uma introdução às dinâmicas da conectividade e da auto-organização. Brasília: WWF Brasil, 2003.

MARTINS, G. A.; THEÓPHILO, C. R. Metodologia da investigação científica para Ciências Sociais Aplicadas. 3 ed. São Paulo: Atlas, 2016.

MARTíN, M. J. M.; JIMÉNEZ-FANJUL, N.; LEÓN-MANTERO, C.; MAZ-MACHADO, A. Revistas brasileiras de educação em Scopus: uma análise bibliométrico. Biblios, Peru, n. 67, p. 30-41, 2017.

NONAKA, I.; TAKEUCHI, H. Criação de conhecimento na empresa. Rio de Janeiro: Elsevier, 1997.

PEIXOTO, A. M. Circulação de saber nas redes sociais informais em organizações privadas: condicionantes e impactos. 2006. Dissertação (Mestrado em Administração) - Programa de Pós-Graduação em Administração, Universidade Federal de Pernambuco, Recife, 2006.

POELL, R. F. et al. Learning-network theory: organizing the dynamic relationships between learning and work. Management learning, v. 31, n. 1, p. 25-49, 2000.

PORTUGAL, S. Contributos para uma discussão do conceito de rede na teoria sociológica. Oficina do CES, Centro de Estudos Sociais, 2007, n. 271. Disponível em: https://estudogeral.sib.uc.pt/bitstream/10316/11097/1/Contributos\%20para\%20uma\%20disc uss\%c3\%a3o\%20do\%20conceito\%20de\%20rede\%20na\%20teoria\%20sociol\%c3\%b3gica.pdf. Acesso em: 14 nov. 2019.

PRODANOV, C. C.; FREITAS, E. C. Metodologia do Trabalho Científico: métodos e técnicas da pesquisa e do trabalho acadêmico. 2 ed. Novo Hamburgo: Feevale, 2013.

RECUERO, R. Redes sociais na Internet. Porto Alegre: Sulina, 2009.

Perspectivas em Gestão \& Conhecimento, João Pessoa, v. 10, número especial, p. 160-175, mar. 2020. 
RODAN, S. Organizational learning: Effects of (network) structure and (individual) strategy. Computational and Mathematical Organization Theory, v. 14, n. 3, p. 222-247, set. 2008.

SANTOS, J. L.; SAMPAIO, R. R. Redes sociais informais e difusão do conhecimento: uma proposta de modelagem em um ambiente de desenvolvimento de projetos de software. Perspectivas em Ciência da Informação, v .21, n. 3, Belo Horizonte Jul/Set., 2016.

SENA, A. C. Processos e redes de aprendizagem em uma organização não governamental. 2010. Dissertação (Mestrado em Administração) - Faculdade de Economia, Administração, Contabilidade e Ciência da Informação e Documentação, Universidade de Brasília, Brasília, 2010.

SILVA, A. K. Redes de coautoria em Ciência da Informação no Brasil: dinâmica na produção científica dos atores mediada pela ANCIB. 262f. 2012. Tese (Doutorado em Ciência da Informação) - Escola de Ciência da Informação, Universidade Federal de Minas Gerais, 2012.

SILVA, J. A.; BIANCHI, M. L. P. Cientometria: a métrica da ciência. Paidéia, v.11, n.21, Ribeirão Preto, 2001.

TOMAÉL, M. I.; ALCARÁ A. R.; DI CHIARA, I. G. Das redes sociais à inovação. Ciência da Informação, Brasília, v. 34, n. 2, p. 93-104, maio/ago., 2005.

URS, S. R.; SHARMA, M. (2010). Making the invisible visible through social network analysis. In: INTERNATIONAL CONFERENCE ON INFORMATION RETRIEVAL \& KNOWLEDGE MANAGEMENT (CAMP), 2010. Shah Alam, Selango: IEEE. doi:10.1109/INFRKM.2010.5466883.

VERMELHO, S. C.; MACHADO VELHO, A. P.; BERTONCELLO, V. Sobre o conceito de redes sociais e seus pesquisadores. Educ. Pesqui., São Paulo, v. 41,n. 4, p. 863- 881, out./dez. 2015.

WAGNER, C. S. The New Invisible College: Science for Development. Washington, DC: The Brooking Institution, 2008.

ZANGISKI, M. A. da S. G.; LIMA, E. P. de; COSTA, S. E. G. da. Aprendizagem organizacional e desenvolvimento de competências: uma síntese a partir da gestão do conhecimento. Produto \& Produção, v. 10, n. 1, p. 54 -74, fev., 2009. 